\title{
Multi-modal transit hubs: enhancing sustainability through joint highway development
}

\author{
A. L. Savvides \\ Department of Architecture, University of Cyprus, Cyprus
}

\begin{abstract}
Transit hubs have always been sites of intense activity and the buildings housing their functions have always held an exotic allure with a character of industrial innovation and structural expression. The central theme of this paper is to address the potential for urban regeneration and improved mobility presented by transit oriented development (TOD) especially as it pertains to the crossroads of highways and transit hubs. This paper also suggests some important qualities of expanded mobility as a smart-growth principle. Expanded mobility is a cornerstone of efforts to promote smart growth. Data has been collected through a survey facilitated by the American Association of State Highway and Transportation Officials (AASHTO), which allowed the solicitation of information on current practices in joined development projects in the USA.

Keywords: urban design, transit oriented development, highway joint development, sustainable development, urban regeneration.
\end{abstract}

\section{Introduction}

In exploring the circumstances that might enable multi-modal transportation nodes at their crossroads with limited access highways to act as the nexus for urban regeneration it is important to define some of the characteristics of their locales. Their catalytic properties will be shown to be a result of their synergistic relationship with Transit Oriented Development (TOD) and Highway Joint Development and their design elements are coupled with the uses that complement this urban typology. 


\section{Definitions}

The (TDM Encyclopedia) describes TOD as the design of residential and commercial centers designed to maximize access by transit and non-motorized transportation. A TOD neighborhood has a center with a rail or bus station, surrounded by relatively high-density development. TOD neighborhoods typically have a diameter of one-quarter to one-half mile, which represents pedestrian scale distances and according to Morris [1] it usually includes the following design features:

- The neighborhood is designed for cycling and walking, with adequate facilities and attractive street conditions and frontages.

- Streets have good connectivity to improve mobility and may include traffic calming features to control vehicle traffic speeds.

- Mixed-use development that includes shops, schools and other public services and a variety of housing types and prices, within each neighborhood.

- Parking management to reduce the amount of land devoted to parking compared with conventional development.

According to Ewing [2] and Cervero et al. [3], Transit Oriented Development generally requires at least 6 residential units per acre in residential areas and 25 employees per acre in commercial centers and about twice that for premium quality transit, such as rail service. These densities create adequate transit ridership to justify frequent service and to promote collective use and commercial activities. The result is an active street life within convenient walking distance of home and work. However, other factors which are discussed later are also important beside simply density. Sometimes density may not suffice to support transit service by itself, but it becomes adequate if implemented with a variety of transit enabling and smart growth strategies.

Highway joint development is defined by the Department of Planning, Environment and Realty of the Federal Highway Administration (FHWA/HEP), as an effort by a public agency and a private developer to undertake a construction project. Joint Developments are usually a voluntary joining of governmental entities with private for-profit organizations to undertake development in connection with public infrastructure. Projects may also be initiated through a co-development. A co-development is an informal working arrangement in which the public agency and the private developer work together to complete their individual projects in a mutually beneficial way. The codevelopers usually attempt to site and coordinate their projects based on a nonbinding legal agreement. A joint development agreement - of the type that has prompted the case studies featured later in the paper - generally contains formal legally binding language between a public entity and a private entity.

\section{Learning from TODs}

In order to further define the differences between a transit-adjacent development and a true transit-oriented development, which will deliver promised social and 
economic benefits, Tumlin and Millard-Ball [4] proposed a set of criteria, summarized as follows:

- The transit-oriented development is located within a five-minute walk of a transit stop - about a quarter-mile from stop to edge (in the case of major transit nodes this may extend to a 10-minute walk).

- A balanced mix of uses generates 24-hour ridership and patronage that extends beyond the 9-to-5 workday. There are places to work, to live, to learn, to relax and to shop for daily needs.

- A place-based zoning code generates buildings that shape and define memorable streets, squares and plazas, while allowing uses to change easily over time.

- The average block perimeter is limited to no more than 1,350 feet, which should generate a network of streets that handle traffic efficiently while keeping the thoroughfares safe.

- Minimum parking requirements are abolished and maximum parking requirements are instituted, such that for every 1,000 employees no more than 500 spaces and as few as 10 spaces are provided.

- Major stops provide bike-stations, offering free attended bicycle parking, rentals and repairs, while enclosed bicycle parking may be provided at minor stops.

- Transit service is fast, frequent and reliable (15 minutes or less with the possibility of accessing train proximity to station via a number of methods), comprising comfortable vehicles.

- Roadway space is allocated and traffic signals timed to encourage use by walkers and cyclists. Roads may be designed to limit speed to 30 mph through traffic calming devices.

Given the criteria above, Transit Oriented Development seems to fit in a particular category of smart growth with a dose of location efficient development and new urbanism principles and current data below supports its policy adoption and implementation. In the past decade transit ridership has increased, revealing a growing interest in transit in a range of city types and locales. These ridership gains, though still behind auto use, point towards a trend in transportation where people are increasingly valuing the option of living in the city and utilizing mass transit. This is further evidenced by the fact that traditional population centers have become more attractive to empty nesters and singles as a place to live; employers as a place to locate; and investors as a place to seek gains in real estate. This resurgence bears significantly on the need for improved mobility assisted by transit. Interest in the metropolitan core can be attributed to many conditions. 2000 Census results show that household size is shrinking, producing more households of empty nesters, singles and non-family residents. While the predominant population pattern is that suburbs grew faster than their central cities, most large cities saw population gains in the 1990s. Urban Land Institute research characterized the movement back to the city as being led by two groups - young tech workers who favor urban living to life in the suburbs and the baby boomers. 
The 1990s also revealed unique challenges for the exurban areas, with increasing requirements for more infrastructure and available workers. In this respect, most major cities offer employers in-place infrastructure and an available workforce with established transit systems that make businesses accessible to all workers. By the mid-90s, these assets became increasingly evident to small and large employers particularly in the growing service sector. According to the 2001 survey of 350 New Economy companies by Jones Lang LaSalle in its Property Futures publication, 77 percent of New Economy companies rated access to mass transit as an extremely important factor in selecting corporate locations. According to the same survey areas with sensible zoning (integrating commercial, retail and residential), parks and street grids with sidewalks will age better than places connected to disconnected cul-de-sac subdivisions and shopping strips, navigable only by car. On the contrary, expanding suburban agglomerations in the Sunbelts can provide developers and investors with short-term opportunities to cash in on growth waves - but the returns, on average, have not been competitive. Markets served with masstransportation alternatives and attractive close-in neighborhoods should be positioned to sustain better long term prospects according to Jones Lang LaSalle. Similarly, the 2001 issue of Price Waterhouse Coopers' Emerging Trends in Real Estate continued to advise investors to seek out opportunities in 24-hour cities, with mixed-use development and mass transit access. Increasingly, real estate investors are looking for value in established communities. Moreover, recent brownfields legislation should improve the interest in existing urbanized locations even more.

The potential for transit oriented development to build economic value and staying power can be seen from the example of Arlington County, VA, in the National Capital region, which has pursued a policy of concentrating its development activity along the Rosslyn-Ballston Corridor since the construction of the Washington Metro. A recent study by TransManagement, Inc. for Great American Station Foundation found that development along transit allowed the County to capture over 13 million square feet of office space and 2 million square feet of retail since 1980. The corridor has increased in population from 19,838 in 1980 to 34,485 in 2000 , reversing a steep population decline in the Seventies. Land value within the corridor near the four stations increased by 81 percent from 1992-2002, an average annual increase of 6.1 percent, generating over $\$ 109$ million in property taxes in 2002 alone. The corridor generates approximately $33 \%$ of the County's real estate tax on $7.7 \%$ of the County's land and vacancy rates were at $10 \%$. This is half of the vacancy rate of suburban office concentrations in other nearby Virginia suburbs. Office rents in the Rosslyn-Ballston Corridor also command a rent premium over other office locations in the Northern Virginia marketplace.

\section{Coupling rail and highway infrastructure}

In the case of coupling highway and transit infrastructure, it can be inferred then that high-quality transit supports the development of high-density urban centers, 
which can provide accessibility and agglomeration benefits - efficiencies that result when many activities are physically close together as stated by Voith [5] and Boroski et al. [6]. Railway station surroundings are the "shop window" of a town, a place where many people see what the community has to offer. It is therefore important that such areas be attractive and inviting to visitors, as welldesigned places are crucial for quality-of-life reasons. By locating stations (and subsequent development therein) around accessible and convenient highway exits and adjacent to public facilities and spaces, a neighborhood can promote safety and comfort through a "strong sense of community, participation, identity and conviviality" as stated by Calthorpe [7].

In examining the coupling of Transit Oriented Development and Highway Joint Development, the preceding data can be considered, adopted and transformed to consider the hybrid for a multi-modal station that adheres in most respects to the principles that govern TODs, yet it attempts to include the use the private automobile as an unavoidable component of the transportation cycle. Highway joint development has only started to occur recently after limited access highway networks came into being and carved their way through cities, railways had made their mark in the urban fabric from the mid-nineteenth century. Consequently some of the opportunities and challenges faced by highway agencies today may be investigated in the context of railway transit corridors.

\section{Surveys and precedent case studies}

A survey was carried out in collaboration with AASHTO, which reveals that departments of transportation and their subsidiaries involved in the selected case studies have set strict design standards, addressing safety and public health, lighting, ventilation, vibration and noise, traffic capacity, maintenance, emergency services and compatibility with the surrounding environment. Moreover, the effects of joint development have been considered both in terms of future expansion of the transportation systems involved as well as maintenance. In order to accommodate a multi-modal transit station that spans rail and/or road right-of-way, certain technical aspects such as air rights construction over the transportation corridor (whether railway or highway or both), involve a number of specific problems and impediments, often as to location, common to all the projects analyzed by Jolliffe $[8,9]$.

In coupling the limited access highway system to the transit function, as mentioned above, the location of efficient access points on and off highway and into the multi-modal stations integrated parking provisions becomes a key. In the case studies examined, the projects actually incorporate highway access ramps within their structural grid and building envelope. These access points are efficiently servicing the air rights structures with integrated or adjacent exits to parking facilities incorporated in the development project. For all the DOTs and city planning agencies interviewed, this has been a conscious decision so as to effect the least impact on the traffic capacity of the system and of the adjacent 
city streets. Traffic capacity requirements for years to come are also carefully considered by traffic engineers early on in the air rights proposal review process.

\section{Towards sustainability through stakeholder collaboration}

Transit Oriented Development usually requires the coordinated support of local governments, private developers and transit agencies. According to the AASHTO survey findings, two factors influenced the decision by the public agencies to proceed with joint development in Boston and Seattle, namely public benefit and development costs. Public benefit requires a decision based on community location and type of use and public demand for services is similar to market demand for private activities. In the metropolitan surveys carried out in the cities of Boston and Seattle, the results indicate that communities are evenly split as to whether neighborhood associations should begin participation in the joint development review process before or after a developer is designated for a specific site. In proposing to proceed with joint development one has to keep three points in mind according to the responses given:

- The first point is that all participating public agencies need sufficient analytical information in order to reach a decision regarding the scope and character of their participation as this necessitates changes in specific planning recommendations of the air rights feasibility study.

- The second point is that for effective citizen participation to take place possible development approaches may be outlined and analyzed and the reasoning behind them clearly outlined to the affected communities so that a preferred strategy may be established for a clear framework to emerge.

- The third point is that specific features of the joint development concepts, renderings and massing models may be presented to community groups and individuals and a series of conferences and meetings held to discuss the implications of and reactions to the proposals.

To achieve these objectives, however, respondents noted that intergovernmental relations and responsibilities might be resolved so that solutions do not cause further disruption or fragmentation to the fabric of the community. The picture that emerges is that of a three-dimensional city, whereby urban space may accommodate human interactions by vertical or sectional travel as well as horizontal or planar travel, which tends to extend travel distances. In this picture, transportation systems form an integral part of the total socioeconomic climate in which users and non-users may be given equal footing. To achieve this, all entities agree that the community to be affected be engaged in deliberation early on and educated on the local as well as metropolitan issues at hand. The costs and benefits of joint development may then be redefined to exploit the unique opportunities in terms of furthering land use planning or community goals and in pursuing social, economic and environmental sustainability. 


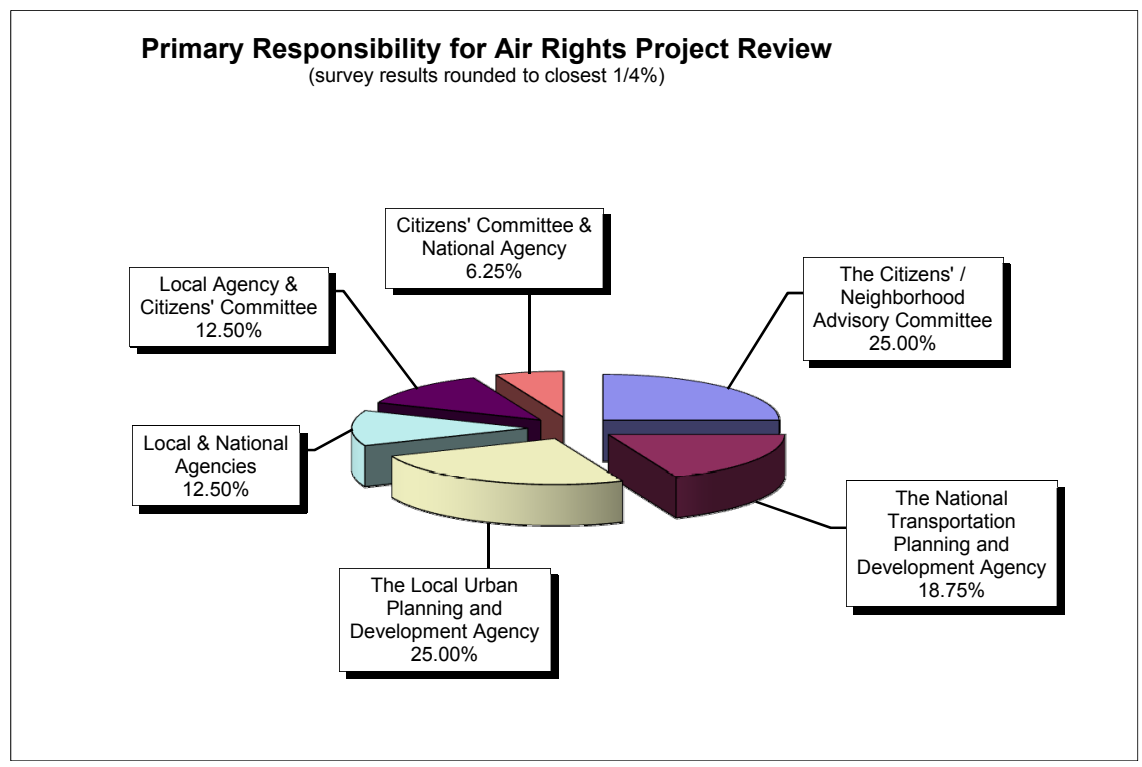

Figure 1: Distribution of metro survey responses; responsibility for air rights project review.

The overlap between the respective planning objectives above signify areas where the true potential of coupling highway joint development and TOD design may be realized. According to Bajracharya and Khan [10] these include: liveability - as intersection between social and environmental goals; community vitality - as overlap between social and economic goals; and resource productivity - as intersection between economic and environmental goals of sustainability. A successfully conceived joint development proposal should aim at creating a place that is liveable, that is inhabited by an economically sound and vibrant community and that is set in an environment where surrounding natural resources are valued and positively exploited. Its strength lies in its ability to apply a framework guided by social, economic and environmental sustainability, which integrates sound planning and urban design principles to achieve the goals of liveability, community vitality and resource productivity. The private development teams as well as metro survey respondents would like specific legislation and an efficient administration before undertaking extensive projects. Specifically, they would like to see in place:

- A plan of action: One course of action is to pursue a development program based on an agreed upon master/concept plan. Such a program is beneficial but also requires supervision of defined responsibilities and objectives. It may also require statutory revisions and cooperation with local authorities.

- A centralized authority: A centralized authority may be created to deal with joint development throughout a metropolitan area to promote efficient development by continued coordination among the various 
public agencies and address the various issues related to the proposed air rights project.

- Local support: Local initiative for air rights proposals may be sought in conjunction with local communities and the local planning agency so as to plan in advance and establish basic development standards on the type and intensity of use. (Figure 1 above shows the distribution of metro-survey responses as to which entity or a hybrid thereof may be entrusted with primary responsibility for air rights project review).

- Private participation: By standardizing requirements, the public authorities may encourage private participation, as the confidence of both the local government and the private industry in the process is increased.

\section{Community considerations}

Table 1 above presents results from metropolitan surveys in Boston and Seattle; results indicate the weighted average and percentage of desirability for each item. The metropolitan survey shows that in an effort to determine priorities for programs to deal with the most critical social issues associated with joint development, about $43.75 \%$ of respondents would like more informal meetings/reviews to present their arguments, while an equal number think that the current format is adequate. Involving people in decision-making about the physical and social environment is more important than the plan, especially in

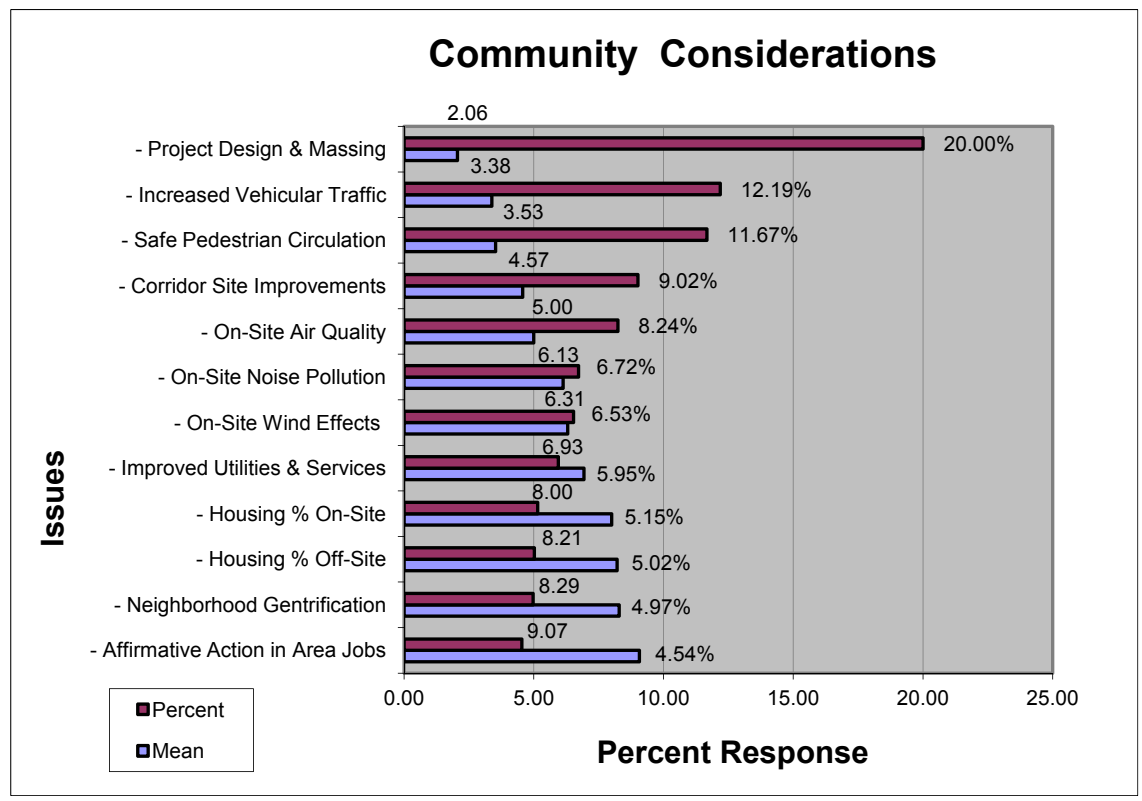

Figure 2: $\quad$ Metro surveys in Boston and Seattle. 
conceiving of a way to address these issues of concern in a comprehensive system. Location criteria then help develop policies that are problem-oriented, addressing current concerns and design concepts are attuned to the goals of the affected neighborhood.

\section{Conclusion}

With that transit terminals and associated highway interchanges may hopefully start drawing on associations for the potential of more air rights proposals over highway corridors in addition to spinning off transit oriented development. Thereafter, as these developments mature they not only have catalytic effects on urban and economic development as mentioned above, but they also promote both urban regeneration and preservation of existing urban fabric in their immediate context and in the transportation corridor in which they are located. Moreover, the seamless and efficient integration of the various transportation systems that converge therein lead to increased and efficient mobility. Beyond that they also transform themselves into readily recognisable areas that define and give character to the urban fabric and promote situational awareness and readability of the city's organization and layout.

Not much field research on air rights development has been carried out in the USA after basic legislation made structures on highway air rights possible in the late 50s. It is for this reason that for this body of work the case study method was identified as the research approach that aims to analyze data on current land use and building conditions in the project areas identified. Information was assembled from cities, which have reached critical densities that can sustain development of the air rights over urban arterials and that have shown innovation in crafting workable public-private agreements. Additional information has been collected through interviews targeting privately funded joint development ventures. The reason for concentrating the research around private ventures stems from the fact that until recently the argument against engaging in joint development of this project typology was the overwhelming contribution of public funds required to make them feasible. According to the public-private teams interviewed this was the mainstream perception up until the first (mostly) private developments started appearing in the 70s and 80s in North America.

\section{Acknowledgements}

The author would like to acknowledge the American Association of State Highway and Transportation Officials (AASHTO) [11] and Boston and Seattle Community Advisory Committees for their assistance in carrying out the "AASHTO" and "Metropolitan" surveys respectively. Thanks also to all those who took the time to participate in informational interviews and to discuss the issues surrounding the joint development of multi-modal transportation nodes. 


\section{References}

[1] Morris, Marya, editor, Creating Transit-Supportive Land-Use Regulations. Planning Advisory Service Report No. 468, American Planning Association, Chicago, IL, 1996.

[2] Ewing, Reid, Pedestrian- and Transit-Friendly Design: A Primer for Smart Growth. Smart Growth Network, Washington, DC, 1999.

[3] Cervero, Robert, et al., Transit-Oriented Development in the United States: Experience, Challenges and Prospects. TCRP Report 102, Transportation Research Board, Washington, DC, 2004.

[4] Tumlin, Jeffrey; Millard-Ball, Adam, How to Make Transit-Oriented Development Work. Planning, Vol. 69, no. 5, 2003.

[5] Voith, Richard, The Downtown Parking Syndrome: Does Curing the Illness Kill the Patient? Business Review, Vol. 1, pp 3-14, 1998.

[6] Boroski, John; Faulkner, Topaz; Arrington B.; Mori, Stuart; Parker, Terry; Mayer, Daniel, Special Report - Parking and TOD: Challenges and Opportunities. Statewide Transit-Oriented Development Study: Factors for Success in California, Business, Transportation and Housing Agency, CalTrans, Sacramento, CA, 2002.

[7] Calthorpe, Peter, The Next American Metropolis: Ecology, Community and the American Dream. Princeton Architectural Press, New York, 1993.

[8] Jolliffe, Michael, Highway Air Rights Construction Adds New Land to Boston. Urban Land, Vol. 43, no.8, pp. 7-9, 1984.

[9] Jolliffe, Michael, Highway air rights structures. Zaldastani Associates, Inc., Boston, MA, 1990.

[10] Bajracharya, Bhishna and Shahed Khan 2005 "Towards a Framework for Evaluating Potential Sites for Transit Supportive Development in South East Queensland" Proceedings of the Conference on Emerging Futures: Smart Transport and Quality Design in Transit Oriented Development organized by The Centre for Transport Strategy, The University of Queensland and Transport Roundtable Australasia, September 2005, Brisbane.

[11] American Association of State Highway and Transportation Officials (AASHTO), www.transportation.org 